\title{
VIRTUAL REHABILITATION - A FOCUS ON MOVEMENT FUNCTION
}

\author{
Gábor Barton \\ Research Institute for Sport and Exercise Sciences \\ Liverpool John Moores University \\ G.J.Barton@ljmu.ac.uk
}

\begin{abstract}
For a long time virtual reality had been an exciting concept commonly associated with science fiction rather than science but with the accelerated development of technology now we have an accessible tool which is used in a multitude of applications. Rehabilitation is one of the fields where physical or intellectual interaction of the patient with a reactive environment can lead to health benefits and so the concept of "virtual rehabilitation" enjoys a lot of attention. The complementary expertise of health professionals, biomechanists, engineers and computer scientists working together in virtual rehabilitation allows us to formalise research questions related to movement function and the answers can help individuals coping with their impairments in a daily living context. This article describes our initial steps on a long and exciting journey.
\end{abstract}

Keywords: virtual reality, rehabilitation, movement analysis, cerebral palsy, targeted training, core control

\section{Introduction}

Our Institute received major funding from the UK's Science Research Investment Fund in 2004 to establish a cutting edge scientific laboratory aiming to extend research towards new directions by combining biomechanical movement analysis technology with virtual reality. This approach has taken us into the exciting arena of "serious games" which are games designed for purposes other than entertainment (see www.seriousgames.org.uk). Packaging a research paradigm as a computer game builds heavily on the power of motivation which together with repetition and feedback provides the three components of motor learning ${ }^{1,2}$. Our initial studies were of technical nature exploring the potential uses of the only CAREN system in the UK but we soon moved on to bona fide research projects in a clinical context. Considerable research funding by The WellChild Trust, Alder Hey Children's NHS Foundation Trust, and LJMU's
Institute for Health Research has consolidated the theme of Virtual Rehabilitation. A brief overview of the past five years will cover the technically focused initial work followed by the more applied research projects closing with an indication of future directions of research.

\section{The CAREN system}

A lot of delicate details of human balance and posture have been uncovered following the conventional scientific approach of breaking down the phenomenon of standing balance into its conceptual building blocks (inputs, processing and outputs) and examining the components in great detail. The complexity of the experiments however is still inferior when compared to the challenges of real life situations where balance seamlessly or consciously plays an integral part of coping with our environment. How a figure skater can land after a 
jump on a narrow blade, how a child learns to ride a bicycle, how a mother can manoeuvre a buggy on a bus braking in a bend, or even how a frail old lady can stand by the kitchen sink with poor vision and painful hips, are all challenges to the experimenter which so far had to be avoided or largely simplified before they could be approached.

Inputs, outputs and the internal processing of the neuro-musculo-skeletal system can be manipulated and evaluated by the integration of a number of sub-systems. Vision, proprioception and the vestibular system are the three inputs to balance and posture and can be influenced by computer generated graphics presented to a subject standing on a computer driven movable Stewart platform. Output of the subject is segmental movement captured in real-time by an optoelectronic multi-camera setup (e.g. Vicon or Qualisys). Advanced computer graphics software (e.g.
SoftImage) can be used to generate faithful scenarios which provide the task for the individual experiencing the interactive environment. The Computer Assisted rehabilitation Environment (CAREN system, www.motekmedical.com) links together all the above components making it possible to set up real time cause-effect relationships and feedback loops of events. For example the Boat demo (Figure 1) uses reflective markers attached to the trunk to reconstruct trunk lean sideways which rolls a boat on the screen and rolls the platform at the same time. Forward tilt of the segment is linked to forward acceleration of the boat. In this example leaning of the trunk moves the supporting platform which in turn moves the trunk, thereby closing a positive feedback loop. Responses of the person immersed in the virtual environment carefully designed to interact with the individual can be recorded and analysed offline.

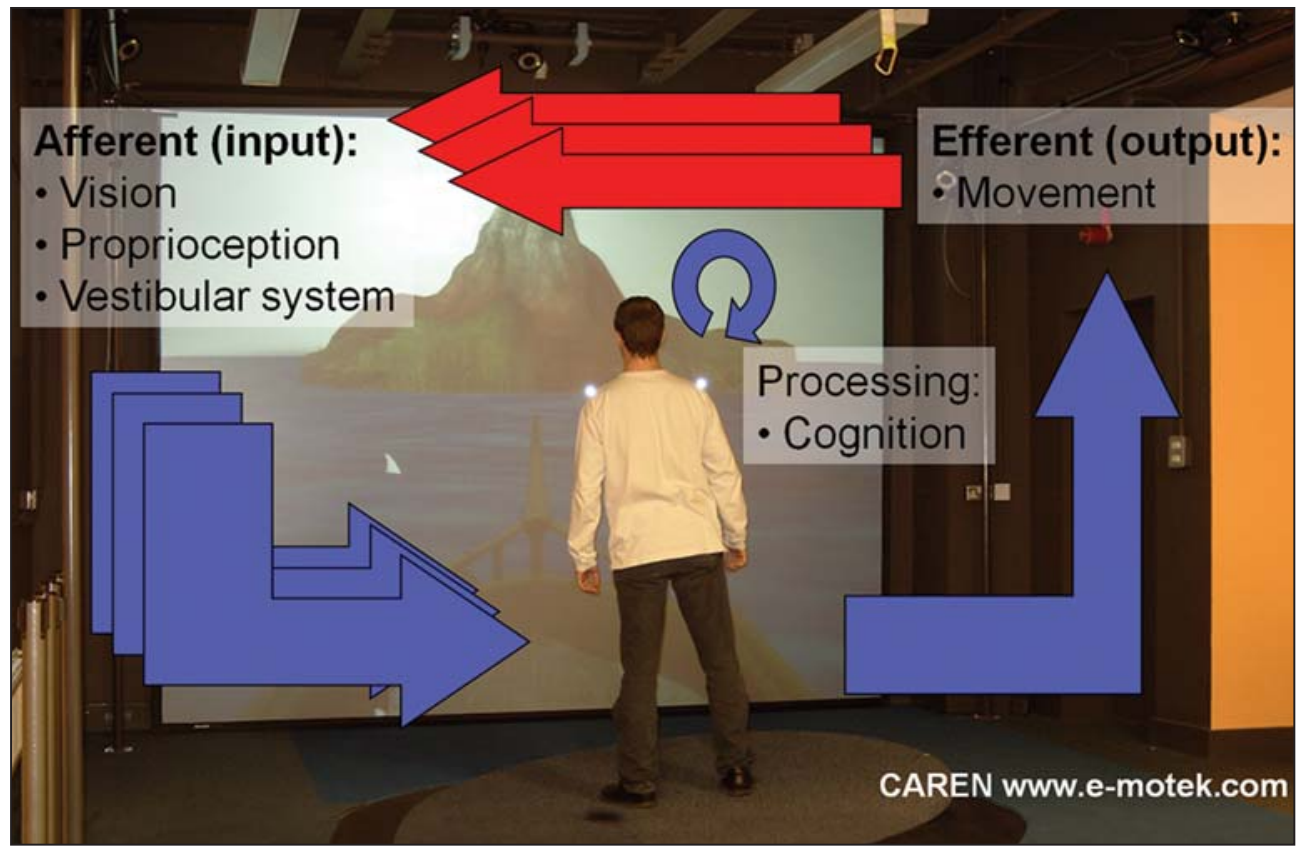

Figure 1. The CAREN system integrates biomechanical movement capture, three dimensional computer graphics and a movable platform to provide immersive virtual environments 


\section{Initial studies}

In one of our earliest studies ${ }^{3}$ we aimed to determine the technical performance of the CAREN platform by defining its kinematic response characteristics to commonly used input functions for each of its six translational and rotational degrees of freedom. Limits of the platform's linear and angular displacement $\left(0.13 \mathrm{~m}\right.$ and $\left.16^{\circ}\right)$, velocity $\left(0.4 \mathrm{~ms}^{-1}\right.$ and $\left.40^{\circ} \mathrm{s}^{-1}\right)$ and acceleration $\left(4.5 \mathrm{~ms}^{-2}\right.$ and $\left.450^{\circ} \mathrm{s}^{-2}\right)$ compare favourably with other single degree of freedom platforms. Full range of the CAREN platform's amplitude can be utilised at $0.3 \mathrm{~Hz}$ sine movement and $25 \%$ of its range at $1.2 \mathrm{~Hz}$. The low maximum average displacement crosstalk (1.5\%) and velocity crosstalk $(3.3 \%)$ suggest that single degree of freedom movements can be generated faithfully although the real strength of the platform is in the generation of realistic multiple degree of freedom movements. In our assessment the CAREN system is an appropriate device for postural and balance research with some unique features.

There is mounting evidence in the literature ${ }^{4}$ that triggered responses to balance perturbations involve not only the ankle but also neck, thigh and trunk muscles. Current research ${ }^{5}$ demonstrated that a single inverted pendulum model of human posture is not sufficient and muscles crossing the ankle, knee and hip account for the majority of forces driving a musculoskeletal model. Such evidence raises the need to generate joint specific rotational perturbations by rotating the CAREN platform around an axis crossing the targeted joint of the subject standing on the moving platform. Our first published results with the CAREN platform ${ }^{6,7,8}$ described locations of the platform's default axes of rotation and the mathematical algorithm needed to translate the three axes of rotations into arbitrary locations. Accuracy of the platform's movement is indicated by the small bounding rectangles containing the instantaneous axes of rotation while rotating around the ankle, knee and hip of a subject standing on the platform (ankle: $1.87 \times 0.81 \mathrm{~mm}$, knee: $3.04 \times 1.23 \mathrm{~mm}$, hip: $3.14 \times 1.63 \mathrm{~mm}$ ).

The ability to aim rotational perturbations of the standing support at specific joints was used to test ${ }^{9}$ if rotation of a person around the hip joint leads to a more focused movement perturbation when compared to the conventional rocking movement routinely used in targeted training ${ }^{10}$. Movement responses of one healthy female participant were recorded under the two conditions replicated by programmed movements of the CAREN platform (Figure 2). In comparison to the rocker movement, rotation of the body around the hip joints resulted in significantly reduced range of motion (ROM) in the hip and spine (mean \pm SD: $1.4^{\circ} \pm 0.3$ and $6.8^{\circ} \pm 1.2$ respec-

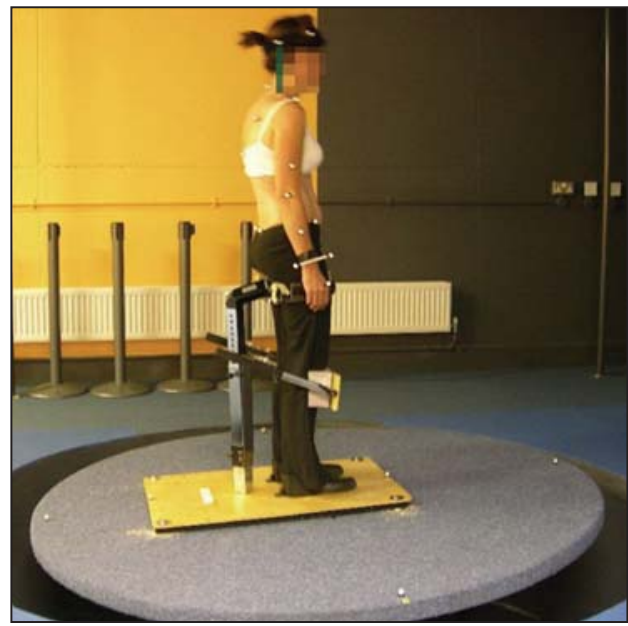

Figure 2. The upper part of a Targeted Training equipment is mounted on the CAREN platform which was programmed to replicate the default rocking movement normally provided by a rocker base. Responses of hip and lumbar flexion/ extension were recorded and compared to a condition in which the body was rotated around an axis joining the two hip joint centres 


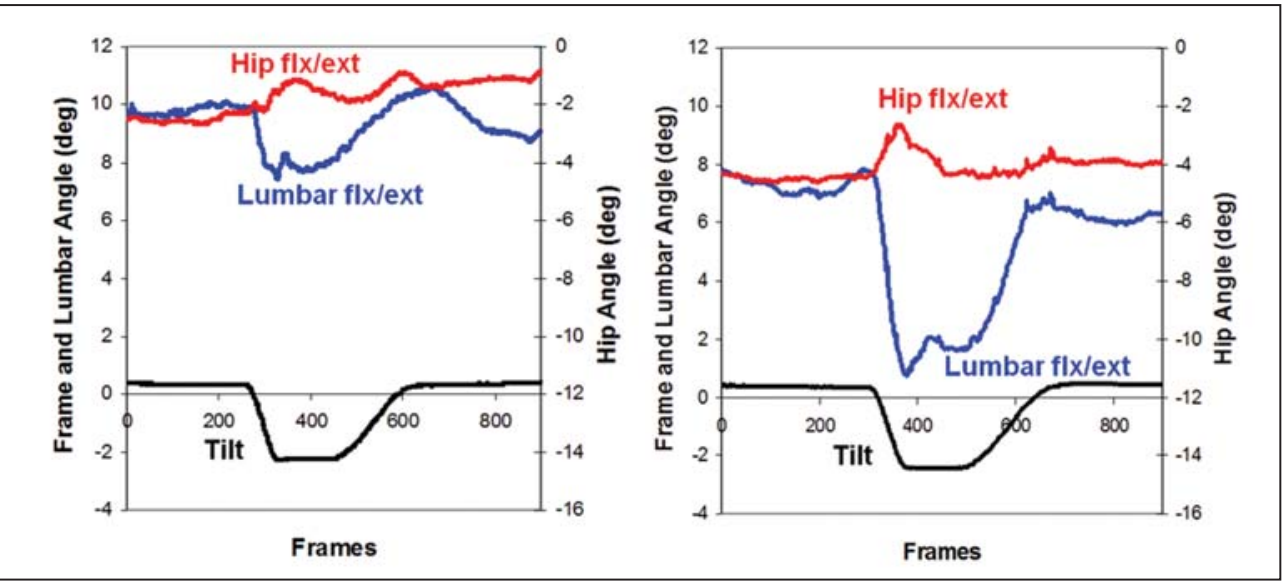

Figure 3. Tilt of the body using the same ramp function (black curve) resulted

in different responses of hip and lumbar movement when rotating around the hip centre (left chart) and simulating the default rocking motion (right chart)

tively when rocking and $1.1^{\circ} \pm 0.4$ and $2.5^{\circ} \pm 0.4$ respectively when rotating, $\mathrm{p}<0.05$ ) and a significantly increased ratio of hip-tospine ROM (mean \pm SD: $0.2 \pm 0.1$ when rocking and $0.5 \pm 0.2$ when rotating, $\mathrm{p}<0.05$ ) (Figure 3). Rotation around the targeted joint simplifies the balance task by minimising the antero-posterior accelerations and related proprioceptive, vestibular and visual stimuli, as indicated by the smaller ROMs. Rotation around the hip joint re-directs the focus of movement perturbation from the spine, confirmed by the increased relative contribution of the hip. The ability to focus the movement perturbation on a selected joint while reducing the stimulus acting on adjacent joints allows more finely graded levels of difficulty when training patients with cerebral palsy (CP).

\section{Virtulal rehabilitation - proof of concept}

A collaboration with the Gait Laboratory of Alder Hey Children's NHS Foundation Trust (Liverpool) and The Movement Centre (Oswestry) resulted in an award winning pres-

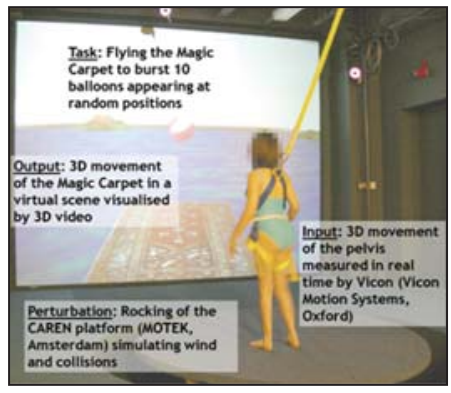

a)

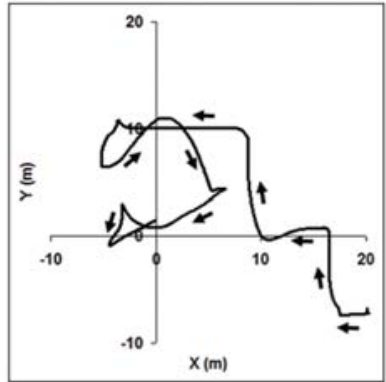

b)

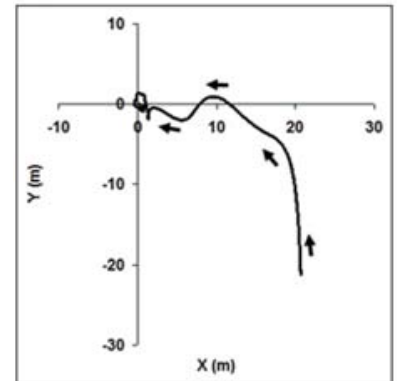

c)

Figure 4. The Magic Carpet game (a) played by a girl with cerebral palsy diplegia.

Typical trajectories of the magic carpet approaching the balloon in the origin, showing the differences between strategies used by the patient $(b)$ and the healthy control $(c)$ 
entation ${ }^{11}$ exploring the potential of Virtual Rehabilitation in cerebral palsy. The study documented our proof of concept findings with a virtual reality game which employed a multiple-task driven visual and somatosensory bio-feedback environment that was expected to serve both as an assessment and training tool for core (pelvic) stability in $\mathrm{CP}$ children. Movement of the pelvis recorded in real time by Vicon was used to navigate the "Magic Carpet" in order to burst a series of balloons appearing at random positions (Figure 4a). A comparison of the movement strategies of a diplegic patient and a typically developing control (Figure $4 b$ and $4 c$ ) indicated that the method had a great potential to evaluate core stability. A video of the game can be seen at www.ljmu.ac.uk/sportandexercisesciences/ RISES/WellChildProject.

\section{Goblin post office - the WellChild project}

Motivated by the initial findings and financially supported by The WellChild Trust, the next stage was to further develop and evaluate custom made computer games to improve movement co-ordination of children with cerebral palsy who have impaired dynamic movement control of the pelvis and trunk (core). We proposed that exposure to computer games driven by active body movements of the core can lead to measurable improvements of core control and gait, and that computer based core control training is more effective than exposure to conventional physiotherapy. In phase 1, games were designed and developed and participants were recruited (Figure 5). In phase 2 after establishing their baseline measures of core control and gait, the CORE group received core control training by playing the games, and the CONTROL group played the games for the same duration and frequency but without a focus on core control (by using a joystick). This phase ended with recording of post-training measures of core control and gait scores. We are currently in phase 3 when the results are analysed leading to output generation.

Related satellite studies have explored the effect of game speed ${ }^{12}$ and the development profiles of performance over time ${ }^{13}$. Our initial results were presented at ESMAC 2009 reporting some findings of the pre-training tests of core control, focusing on rotation and tilt of the trunk and pelvis ${ }^{14}$. The game task was similar to that of the "Magic Carpet"
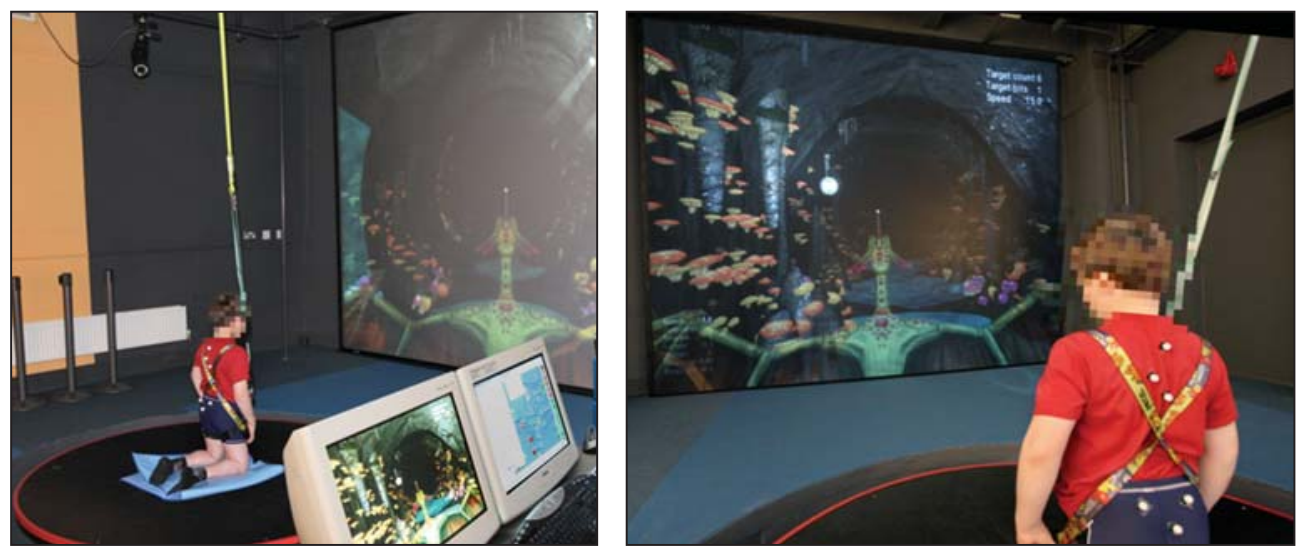

Figure 5. One of our participants playing the Goblin Post Office game.

Note the two clusters of markers on the trunk and pelvis which drive the game 
game with the added feature that an adaptive algorithm adjusted the speed of the game in response to changes in target hit rates during game play. The maximum settled speed reached under each segmental control scheme was used to quantify performance. Significant differences were found between the control schemes in that game speed with trunk rotation was highest $\left(54.5 \pm 0.6 \mathrm{~ms}^{-1}\right)$ followed by trunk tilt $\left(48.3 \pm 2.0 \mathrm{~ms}^{-1}\right)$ and then pelvic rotation $\left(44.1 \pm 1.6 \mathrm{~ms}^{-1}\right)$. Children were unable to play the game using pelvic tilt. Sagittal plane tilt was more difficult to control than transverse plane rotation, the trunk was better controlled than the pelvis, and there was least control over movements of the pelvis.

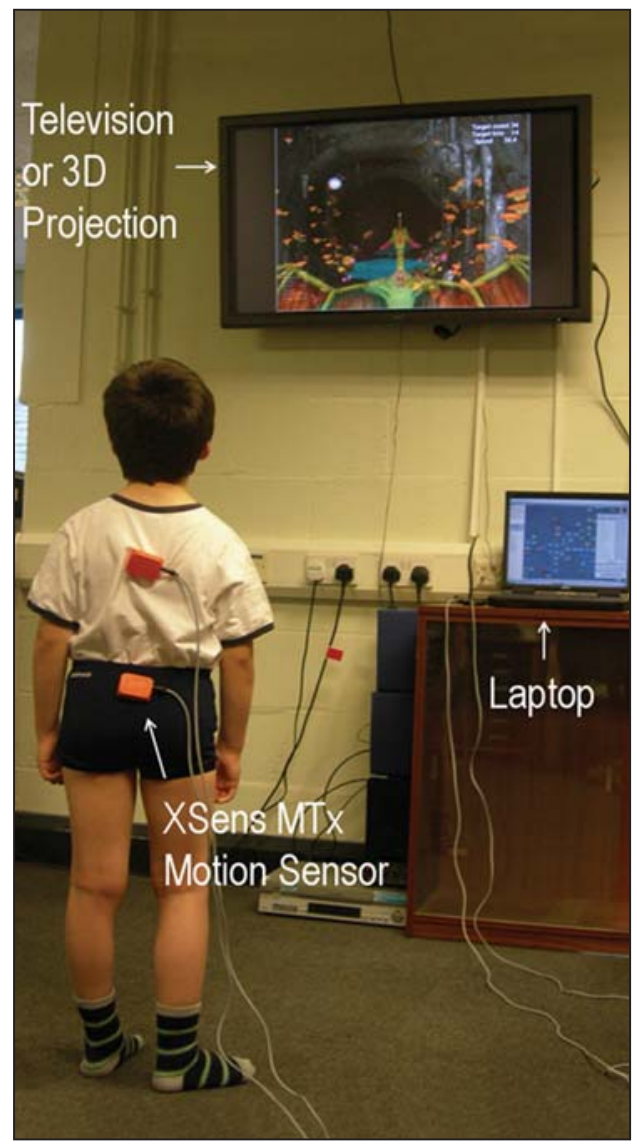

Further results of the study will follow soon and our next project funded by LJMU's Institute for Health Research is under way aiming to extend movement training to peripheral joints in order to improve reduced selectivity of muscle control in children with cerebral palsy. Our newly developed games training methodology based on inertia sensors (XSens, Enschede, The Netherlands) will be applied in Liverpool schools accessing more children (Figure 6). We aim to describe the interaction between core and peripheral movement control measuring the specific effects of the interventions on selective movement control. The specific implementation of virtual reality based movement training in clinical and community settings was funded by Alder Hey Charitable Funds.

\section{Future directions}

Our current research stream uses visual and somatosensory feedback based on segmental movement. Thanks to the recent developments by Motek Medical, their Human Body Model software can visualise muscle actions in real time derived from inverse dynamics (joint moments and powers) combined with optimisation algorithms (Figure 7). Muscle specific visual bio-feedback realised in flexible virtual environments opens new directions to improving the movement control of children with neuromuscular conditions.

Figure 6. The Goblin Post Office game running on a laptop computer can be driven by XSens orientation trackers.

Strategic placement of the sensors to selected body segments can be used to address the role of core and peripheral movement control in motor learning 


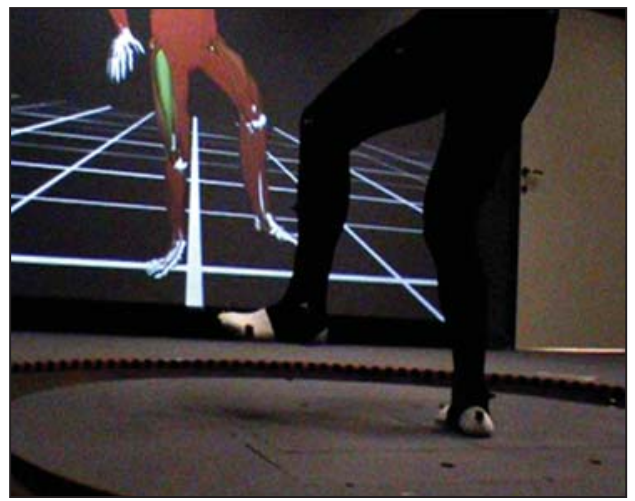

Figure 7. Motek Medical's Human Body Model in action. The colour of each muscle indicates its activation level calculated in real time from inverse dynamics using an optoelectronic movement analysis system and two force platforms. Addition of an instrumented treadmill with dual force platforms enables visualisation of muscle activity during gait

\section{REFERENCES}

1. Rizzo AA, Buckwalter $G$, van $\operatorname{der} Z a a g C$. Virtual environment applications in clinical neurophysiology. In: Stanney K, editor. Handbook of virtual environment technology. London: Lawrence Erlbaum; 2002. p. 1027-64.

2. Holden MK. Virtual environments for motor rehabilitation: review. Cyberpsychology and Behavior 2005;8:187-211.

3. Lees A, Vanrenterghem J, Barton GJ, Lake M. Kinematic response characteristics of the CAREN moving platform system for use in posture and balance research. Medical Engineering and Physics 2007;29(5):629-35.

\section{Allum JH, Bloem BR, Carpenter MG, Hulliger M,} Hadders-Algra M. Proprioceptive control of posture: a review of new concepts. Gait and Posture 1998;8:214-42.

5. Jansen $K$, Levin $O$, De Groote F, Duysens J, Jonkers I. Modelling postural control: Validity of the inverted pendulum assumption. Gait and Posture 2009 (In Press). 18 ${ }^{\text {th }}$ ESMAC Meeting and Conference; Sept 17-19; London, United Kingdom.

6. Barton GJ, Vanrenterghem J, Lees A. Joint specific proprioceptive perturbation of standing balance on a movable platform [abstract]. Gait and Posture 2005;22(Suppl 1):50. 14 $4^{\text {th }}$ ESMAC Meeting and Conference, Sept 22-24; Barcelona, Spain.
7. Vanrenterghem J, Barton GJ, Lake M, Lees A. Changing the axes of rotation in a six degrees of freedom moving platform used for postural research [abstract]. Gait and Posture 2005;21 (Suppl 1):152. ISPGR $17^{\text {th }}$ Conference; May 29June 2; Marseille, France.

\section{Barton GJ, Vanrenterghem J, Lees A, Lake M.} A method for manipulating a movable platform's axes of rotation: a novel use of the CAREN system. Gait and Posture 2006; 24(4):510-4.

9. Barton GJ, Butler PB, Hawken MB, Jarvis SE. Re-direction of movement perturbation by rotating around the targeted joint [abstract]. Journal of Sports Sciences 2009;27(Suppl 1): $3-4$. The Ergonomics Society: $6^{\text {th }}$ International Conference on Sport, Leisure and Ergonomics. 2007 Nov 14.

10. Butler PB. A preliminary report on the effectiveness of trunk targeting in achieving independent sitting balance in children with cerebral palsy. Clinical Rehabilitation 1998;12(4): 281-93.

11. Barton GJ, Holmes G, Hawken M, Lees A, Vanrenterghem J. A virtual reality tool for training and testing core stability: a pilot study [abstract]. Gait and Posture 2006;24(Suppl 2): 101-2. $1^{\text {st }}$ Joint ESMAC-GCMAS Meeting; 2006 Sept 28-30; Amsterdam, Netherlands: Winner of the Best Poster Prize. 
12. Hawkins PJR, Hawken MB, Barton GJ. Effect of game speed and surface perturbations on postural control in a virtual environment. Proceedings of the $7^{\text {th }}$ ICDVRAT with ArtAbilitation; 2008; Maia, Portugal.

13. Foster RJ, Hawken MB, Barton GJ. Movement Co-ordination of the pelvis in a virtual game environment [abstract]. Gait and Posture 2008;
28:10-1. $17^{\text {th }}$ ESMAC Meeting and Conference; Sept 11-13; Antalya, Turkey.

14. Barton GJ, Hawken MB, Butler P, Holmes G, Foster RJ. Movement control of the trunk and pelvis in cerebral palsy diplegia [abstract]. Gait and Posture 2009 (In Press). 18 ${ }^{\text {th }}$ ESMAC Meeting and Conference; Sept 17-19; London, United Kingdom.

Our research is funded by The WellChild Trust, Alder Hey Children's NHS Foundation Trust, and the Institute for Health Research of Liverpool John Moores University.

\section{Dr. Gábor Barton}

Research Institute for Sport and Exercise Sciences

Liverpool John Moores University

15-21 Webster Street, Liverpool, L3 2ET, United Kingdom

Tel: $+44(0) 1512314333$

\section{ALFÖLDI NYOMDA ZRT.}

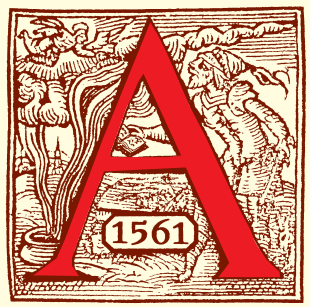

4027 Debrecen, Böszörményi út 6.

Tel.: (52) 515-715 • 415-579

Fax: (52) 325-227 • 430-987

E-mail: info@anyrt.hu

www.alfoldi-nyomda.hu

\section{Teljes körú nyomdaipari szolgáltatás - felsófokon}

